\title{
A case series of pregnancy- and lactation- associated osteoporosis and a review of the literature
}

\author{
Yukio Nakamura ${ }^{1,2}$ \\ Mikio Kamimura ${ }^{3}$ \\ Shota Ikegami' \\ Keijiro Mukaiyama ${ }^{4}$ \\ Masatoshi Komatsu' \\ Shigeharu Uchiyama' \\ Hiroyuki Kato' \\ 'Department of Orthopaedic \\ Surgery, Shinshu University School of \\ Medicine, Matsumoto, ${ }^{2}$ Department \\ of Orthopaedic Surgery, Showa Inan \\ General Hospital, Komagane, ${ }^{3}$ Center \\ of Osteoporosis and Spinal Disorders, \\ Kamimura Clinic, Matsumoto, \\ ${ }^{4}$ Department of Orthopaedic Surgery, \\ Azumi General Hospital, Azumino, \\ Japan
}

Correspondence: Yukio Nakamura Department of Orthopaedic Surgery, Shinshu University School of Medicine, Asahi 3-I-I, Matsumoto 390-862I, Japan Tel +8I 263372659

Fax +8I 263358844

Email yxn 14@aol.jp
This article was published in the following Dove Press journal:

Therapeutics and Clinical Risk Management

7 September 2015

Number of times this article has been viewed

\begin{abstract}
The syndrome of pregnancy- and lactation-associated osteoporosis is a rare disorder whose precise etiology and treatment are largely unknown. We herein report two such cases occurring in the early postpartum period that led to multiple fragility compression fractures. Combination therapy of vitamin $\mathrm{D}$ and vitamin $\mathrm{K}$ enabled a marked gradual increase in bone mineral density.
\end{abstract}

Keywords: fracture, vitamin D, vitamin K, bone mineral density

\section{Introduction}

The syndrome of pregnancy- and lactation-associated osteoporosis (OP) is a rare disorder occurring in late pregnancy and the early postpartum period that leads to fragility fractures, most commonly in the vertebral bodies. ${ }^{1,2}$ Approximately 100 cases of pregnancy- and lactation-associated OP have been described to date. ${ }^{3}$

The main complaint in this syndrome is severe pain in the lower back, hips, and lower extremity joints, accompanied by reduced general mobility. However, pain appearing in the final trimester of pregnancy or immediately postpartum is often diagnosed not as an OP-related fracture, but rather as another problem associated with pregnancy and lactation. Although vertebral fractures, regardless of osteoporotic or other causes, are rare complications in new and expecting mothers, they should always be considered in women presenting with an acute pain in the peripregnancy period. ${ }^{1,2}$ Several groups have analyzed the pathophysiology and treatment of pregnancy- and lactation-associated OP. ${ }^{4-6}$ Despite this, the precise cause of this syndrome remains unknown.

With regard to treatment, various drugs have been described for patients with OP. $1 \alpha(\mathrm{OH})$ vitamin D3 (alfacalcidol [ALF]) is an active vitamin D3 analog that is frequently used for OP in Japan, as is vitamin K (menatetrenone) (Glakay, $45 \mathrm{mg} /$ day). More aggressive treatments for OP include bisphosphonates (BPs) and parathyroid hormone (teriparatide). ${ }^{7}$

In this report, we present the clinical findings of two patients with pregnancy- and lactation-associated OP manifesting in the early postpartum period that presumably led to pain and multiple fragility compression fractures.

\section{Materials and methods}

Among the patients presenting at our institution with multiple peripartum vertebral fractures, two were selected for this study. 
Bone mineral density (BMD) was measured using a dual-energy X-ray absorption fan-beam bone densitometer (Lunar Prodigy; GE Healthcare Bio-Sciences Corp., Piscataway, NJ, USA) at the lumbar 1-4 levels of the posteroanterior spine and bilateral hips. Radiographic fractures were evaluated by semiquantitative (SQ) assessment. ${ }^{8}$ Serum bone alkaline phosphatase (BAP) and N-terminal propeptide of type I procollagen were measured as bone formation markers using a chemiluminescent enzyme immunoassay and antibody radioimmunoassay, respectively. Serum tartrate-resistant acid phosphatase-5b and urinary N-terminal telopeptide of type I collagen (NTX) (Osteomark; Osteox International, Seattle, WA, USA) were assessed as markers of bone resorption using the enzyme-linked immunosorbent assay. Serum $1,25(\mathrm{OH})_{2} \mathrm{D}_{3}$ was evaluated by immunoradiometric assays. Each marker was measured just before treatment and at 1 week, 1 month, 2 months, and 4 months afterward. After overnight fasting, serum and first-void urine samples were collected between 8:30 am and $10 \mathrm{am}$. Immunoassays were performed by SRL, Inc. (Tokyo, Japan). Bone turnover markers were regularly analyzed in this study every several to 6 months during the first year and once every 1 to 2 years from the second year. BMD was measured every 6 months. The institutional ethics committees of the Showa-Inan general hospital approved the present study, and informed written consent was obtained from both subjects.

\section{Case presentations Case I}

The patient was 30 years old at symptom onset. Her height and weight were $150 \mathrm{~cm}$ and $50 \mathrm{~kg}$, respectively. Two months after the delivery of her first child, she began experiencing back pain without any apparent cause. Since her pain was unbearable during movement, she was forced to stop breastfeeding. The pain markedly improved over the following 8 months without any particular treatment. She visited our institution at 10 months after pain onset. She was not undergoing any habitual calcium supplementation.

We witnessed 12 fractures (three of grade 1, eight of grade 2 , and one of grade 3) in initial spinal radiographs evaluated by SQ assessment. Lumbar BMD (L-BMD) was low at $0.675 \mathrm{~g} / \mathrm{cm}^{2}$ (-3.6 standard deviation [SD]), while bilateral hip BMD (H-BMD) was mildly decreased at $0.768 \mathrm{~g} / \mathrm{cm}^{2}$ $(-1.4 \mathrm{SD})$. Although urinary NTX was increased, $25(\mathrm{OH}) \mathrm{D}$ was within normal range. The patient began ALF treatment at $0.5 \mathrm{mg} /$ day. Four months later, her results for urinary NTX were unchanged, but undercarboxylated osteocalcin (ucOC)
Table I Background information of case I and case 2 ahead of this study

\begin{tabular}{llll}
\hline Variable (unit) & Reference value & Case I & Case 2 \\
\hline Age (years) & & 31 & 37 \\
BMI $\left(\mathrm{kg} / \mathrm{m}^{2}\right)$ & & 22.2 & 21.6 \\
$\mathrm{I}, 25(\mathrm{OH})_{2} \mathrm{D}(\mathrm{pg} / \mathrm{mL})$ & $20-60$ & 35.6 & 37.6 \\
$25(\mathrm{OH}) \mathrm{D}(\mathrm{ng} / \mathrm{mL})$ & $7-4 \mathrm{I}$ & 27 & 27 \\
$\mathrm{ucOC}(\mathrm{ng} / \mathrm{mL})$ & $<4.5$ & 28.1 & 6.33 \\
u-NTX $(\mathrm{pmol} / \mathrm{mmol})$ & $9.3-54.3$ & 58 & 59 \\
BAP $(\mathrm{U} / \mathrm{L})$ & $9.6-35.4$ & 42.6 & 37.4 \\
AL-P $(\mathrm{IU})$ & $\mathrm{II}-360$ & 358 & 217 \\
Corrected Ca $(\mathrm{mg} / \mathrm{dL})$ & $8.6-10.1$ & 8.8 & 8.8 \\
P (mg/dL) & $2.5-4.6$ & 3.7 & 3.9 \\
\hline
\end{tabular}

Notes: Only ucOC in case I was measured at 4 months after treatment. All of the data in case 2 were measured at I month after treatment with alfacalcidol. Serum Ca was corrected by albumin.

Abbreviations: BMI, body mass index; BAP, bone alkaline phosphatase; ucOC, undercarboxylated osteocalcin; u-NTX, urinary NTX; AL-P, alkaline phosphatase; $\mathrm{P}$, phosphorous.

was increased at $28.1 \mathrm{~g} / \mathrm{cm}^{2}$. Vitamin $\mathrm{K}(30 \mathrm{mg} /$ day) was added to ALF. Thereafter, urinary NTX and ucOC values gradually decreased, although the latter remained elevated at $5.72 \mathrm{~g} / \mathrm{cm}^{2}$ even at 4 years of treatment. At 6 years of follow-up, L-BMD had markedly increased to $0.922 \mathrm{~g} / \mathrm{cm}^{2}$ ( $-1.6 \mathrm{SD}$; increasing rate [IR]: $36.6 \%)$. The IR of H-BMD was $9.5 \%$. The patient did not suffer from any additional pain or de novo fractures during the time of treatment, nor did she exhibit any signs of radiographic vertebral fracture (Tables 1-3).

\section{Case 2}

The patient was 37 years old at symptom onset. Her height and weight were $152.3 \mathrm{~cm}$ and $50 \mathrm{~kg}$, respectively. She had been taking medication for hypothyroidism. Two months after delivering her first child, she began experiencing severe lower back pain when holding the child. She was diagnosed as having a spinal fracture and hospitalized for 2 months. During this period, she stopped breast-feeding, and her pain became completely resolved 18 months after

Table 2 Changes in BMD values

\begin{tabular}{lll}
\hline BMD value & Case I & Case 2 \\
\hline L-BMD $\left(\mathrm{g} / \mathrm{cm}^{2}\right)$ & 0.675 & 0.662 \\
L-BMD $(\mathrm{SD})$ & -3.6 & -3.7 \\
L-BMD after 6 years of treatment $\left(\mathrm{g} / \mathrm{cm}^{2}\right)$ & 0.992 & 0.855 \\
IR of L-BMD after 6 years of treatment & $36.6 \%$ & $29.2 \%$ \\
H-BMD $\left(\mathrm{g} / \mathrm{cm}^{2}\right)$ & 0.768 & 0.794 \\
H-BMD $(\mathrm{SD})$ & -1.4 & -1.2 \\
H-BMD after 6 years of treatment $\left(\mathrm{g} / \mathrm{cm}^{2}\right)$ & $0.84 \mathrm{I}$ & 0.896 \\
IR of H-BMD after 6 years of treatment & $9.5 \%$ & $12.8 \%$ \\
\hline
\end{tabular}

Abbreviations: $B M D$, bone mineral density; $H-B M D$, hip BMD; IR, increasing rate; L-BMD, lumbar BMD; SD, standard deviation. 
Table 3 Changes of u-NTX and ucOC level at each time point before and after treatment

\begin{tabular}{lcccccc}
\hline & $\mathbf{0}$ & $\mathbf{4} \mathbf{~ m}$ & $\mathbf{1 0} \mathbf{~ m}$ & $\mathbf{2} \mathbf{y}$ & $\mathbf{4}$ y & $\mathbf{5} \mathbf{~ y}$ \\
\hline Case I & & & & & & \\
u-NTX $(\mathrm{pmol} / \mathrm{mmol})$ & 58 & 60.6 & 59.1 & 41.4 & 43.6 & 33.9 \\
ucOC $(\mathrm{ng} / \mathrm{mL})$ & & 28.1 & 7.03 & 5.9 & 5.72 & 3.91 \\
Case 2 & & & & & & \\
u-NTX $(\mathrm{pmol} / \mathrm{mmol})$ & 37.6 & 31 & & 15.3 & 24.5 & 26.8 \\
ucOC $(\mathrm{ng} / \mathrm{mL})$ & 6.33 & 3.11 & & 1.49 & 1.7 & 1.97
\end{tabular}

Note: The variables $(0,4 \mathrm{~m}, 10 \mathrm{~m}, 2 \mathrm{y}, 4 \mathrm{y}$, and $5 \mathrm{y})$ are time points at which the researchers examined bone markers.

Abbreviations: ucOC, undercarboxylated osteocalcin; u-NTX, urinary NTX; $y$, year; m, month.

onset. Treatment consisted of rest and external fixation with the use of a lumbar supporter. She was found to have OP 7 months after pain onset in a separate hospital and began taking $0.5 \mathrm{mg} /$ day ALF. She did not feel any pain at that time and was referred to our institution 1 month later. She was not undergoing any habitual calcium supplementation.

In spinal radiographs evaluated by SQ assessment, we observed eight fractures (three of grade 1 and five of grade 2). L-BMD was low at $0.662 \mathrm{~g} / \mathrm{cm}^{2}(-3.7 \mathrm{SD})$, and H-BMD was mildly depressed at $0.794 \mathrm{~g} / \mathrm{cm}^{2}(-1.2 \mathrm{SD})$. Although urinary NTX and ucOC were increased, vitamin D values were normal at her first visit. She soon began vitamin $\mathrm{K}$ with ALF. At 4 months of treatment, urinary NTX and ucOC had greatly decreased. At 6 years of follow-up, L-BMD had markedly increased to $0.855 \mathrm{~g} / \mathrm{cm}^{2}(-2.2 \mathrm{SD}$; IR: $29.2 \%)$. The IR of H-BMD was $12.8 \%$. The patient did not exhibit any pain or de novo fractures after starting treatment (Tables 1-3).

\section{Discussion}

This report presents the clinical findings of two cases of pregnancy- and lactation-associated OP during the early postpartum period that led to multiple fragility compression fractures. More than 6 years of observation have elapsed since the patients began treatment at our institution. In addition to rest and external fixation, $1,25(\mathrm{OH})_{2} \mathrm{D}_{3}$ and vitamin $\mathrm{K}$ greatly improved the IR of L-BMD by $36.6 \%$ and $29.2 \%$, respectively. We previously described that the serum ucOC became elevated in patients with post-pregnancy OP. ${ }^{9}$ Accordingly, ucOC and urinary NTX decreased in both cases.

Pregnancy- and lactation-associated OP is a rare disorder that is believed to cause fragility fractures. ${ }^{10}$ Although the etiology of this syndrome has yet to be defined, familial studies suggest that hereditary factors are involved in pathogenesis. ${ }^{11}$ Another hypothesis is that pregnancy is merely a stressor which unmasks preexisting OP. ${ }^{12}$ The changes in calcium metabolism during pregnancy might also contribute to the onset of pregnancy- and lactation-associated OP. ${ }^{13,14}$

BP administration is most commonly performed for the treatment of pregnancy- and lactation-associated OP. ${ }^{15}$ BPs are regarded as the most suitable drug for patients with low BMD and past fractures with post-pregnancy OP; ibandronate, clodronate, pamidronate, neridronate, and alendronate have all been used successfully in conjunction with calcium and vitamin D supplements in patients with transient, including pregnancy-period, OP. ${ }^{16-19}$

When treating pregnancy- and lactation-associated $\mathrm{OP}$, it is paramount to: 1) prevent vertebral fractures; and 2) increase BMD and resistance to fractures. We could not perform preventative fracture treatment since the injuries had already occurred before presentation. As a result, the patients had suffered from 12 and eight vertebral fractures, respectively. Although osteoporotic treatment was also not given, the chain reaction of fractures had ceased by the time of the first visit at our institution.

Regarding the prevention of subsequent fractures, Winarno et al recently described a case of severe pregnancyand lactation-associated OP with eleven vertebral fractures. According to the authors, unsatisfactory results were obtained with oral and intravenous BPs in combination with calcium and vitamin D supplementation. ${ }^{20}$ These findings indicate that BPs may not be able to halt the development of subsequent fractures.

In contrast, teriparatide is one of the most effective drugs in preventing spinal fractures in osteoporotic treatment. Choe et al reported that daily teriparatide should be considered for young patients with pregnancy- and lactation-associated OP, especially those with multiple vertebral fractures, to avoid long-term morbidity. ${ }^{21}$ In another study, teriparatide treatment resulted in an increase in BMD and no additional fractures during observation over several years. ${ }^{20}$ Indeed, teriparatide is a strong candidate for patients with pregnancyand lactation-associated OP and fractures, ${ }^{20,21}$ but no drugs have been established to inhibit fracture within half a year of OP onset.

BPs and various other drugs have been used for patients with pregnancy- and lactation-associated OP. ${ }^{20}$ Interestingly, the IR of BMD appears to plateau relatively soon during BP therapy. In one investigation, while the 10-year increase in BMD with $10 \mathrm{mg}$ doses of ALN was $13.7 \%$, half of this improvement was attained in the first few years of treatment. ${ }^{20}$ BMD gains are moderate with conventional OP treatment. Teriparatide is more effective than BPs with respect to BMD increase ${ }^{22}$ but has a limited period of use. Thus, it alone may 
not be able to treat pregnancy- and lactation-associated OP. The present study indicates that combination therapy of vitamins $\mathrm{D}$ and $\mathrm{K}$ may be of benefit to increase BMD in such patients.

Serum ucOC is an index of vitamin K nutritional status in treatment-naïve postmenopausal osteoporotic women. The effects of vitamin $\mathrm{K} 2$ on bones are an improvement in bone quality by promotion of osteocalcin $\gamma$-carboxylation and the advancement of bone formation and calcification through steroid and xenobiotic receptors. ${ }^{23}$ Another report found that vitamin $\mathrm{K} 2$ effectively prevented fractures and sustained BMD in OP. ${ }^{24}$ In this study serum ucOC values were elevated in both patients at the onset of treatment. Furthermore, in spite of long-term treatment with vitamin $\mathrm{K}$, one patient had persistently raised levels of this marker. These results suggest that serum vitamin $\mathrm{K}$ level or its metabolic effects might influence the pathophysiology of pregnancyand lactation-associated OP.

Tsuchie et al were the first to report on the effects of vita$\min \mathrm{K}$ in a patient with pregnancy- and lactation-associated OP. ${ }^{25}$ They mentioned that vitamin $\mathrm{K} 2$ was an option for OP treatment, albeit a mild one, to increase BMD. Iwamoto et al later described remarkable augmentations in BMD by ALF administration. ${ }^{26}$ In the present patients with pregnancy- and lactation associated OP, therapy with active vitamin D3 and vitamin $\mathrm{K}$ was associated with an improvement in BMD.

\section{Conclusion}

Our results of two cases of pregnancy- and lactation-associated OP with multiple vertebral compression fractures demonstrated: 1) high values of ucOC, regardless of vitamin $\mathrm{K}$ administration; 2) normal levels of $1,25(\mathrm{OH})_{2} \mathrm{D}_{3}$ and $25(\mathrm{OH}) \mathrm{D}$; and 3$)$ an association between therapy with active vitamin D3 and vitamin $\mathrm{K}$ and an improvement in BMD. Along with marked BMD amelioration, the patients have not displayed any obvious OP-related symptoms since beginning treatment more than 6 years ago. Thus, treatment using active vitamin $\mathrm{D}$ and vitamin $\mathrm{K}$ may be effective to increase BMD and prevent de novo fractures in patients with pregnancy- and lactation-related OP.

\section{Disclosure}

The authors report no conflicts of interest in this work.

\section{References}

1. Bonacker J, Janousek M, Kröber M. Pregnancy-associated osteoporosis with eight fractures in the vertebral column treated with kyphoplasty and bracing: a case report. Arch Orthop Trauma Surg. 2014;134:173-179.
2. Ozturk C, Atamaz FC, Akkurt H, Akkoc Y. Pregnancy-associated osteoporosis presenting severe vertebral fractures. J Obstet Gynaecol Res. 2014;40:288-292.

3. O’Sullivan SM, Grey AB, Singh R, Reid IR. Bisphosphonates in pregnancy and lactation-associated osteoporosis. Osteoporos Int. 2006;17: 1008-1012.

4. Tanriover MD, Oz SG, Sozen T. Ten-year follow-up in pregnancy and lactation-associated osteoporosis: sequential therapy with strontium ranelate and ibandronate. Spine J. 2015;15:1164-1165.

5. Sanz-Salvador L, García-Pérez MÁ, Tarín JJ, Cano A. Bone metabolic changes during pregnancy: a period of vulnerability to osteoporosis and fracture. Eur J Endocrinol. 2015;172:R53-R65.

6. Michalakis K, Peitsidis P, Ilias I. Pregnancy- and lactation-associated osteoporosis: a narrative mini-review. Endocr Regul. 2011;45: 43-47.

7. Mori S. [Concomitant treatment of the osteoporotic drugs]. Clin Calcium. 2012;22:904-910. Japanese.

8. Genant HK, Wu CY, van Kuijk C, Nevitt MC. Vertebral fracture assessment using a semiquantitative technique. J Bone Miner Res. 1993;8: 1137-1148

9. Kamimura M, Uchiyama S, Nakagawa H. The bone metabolic conditions in pregnancy and lactation-associated osteoporosis. Orthopedic Surgery. 2011;VII:189-192. Japanese.

10. Zarattini G, Buffoli P, Isabelli G, Marchese M. Pregnancy-associated osteoporosis with seven vertebral compression fractures, a case treated with strontium ranelate. Clin Cases Miner Bone Metab. 2014;11: 139-141.

11. Dunne F, Walters B, Marshall T, Heath DA. Pregnancy associated osteoporosis. Clin Endocrinol (Oxf). 1993;39:487-490.

12. Khastgir G, Studd JW, King H, et al. Changes in bone density and biochemical markers of bone turnover in pregnancy-associated osteoporosis. Br J Obstet Gynaecol. 1996;103:716-718.

13. Di Gregorio S, Danilowicz K, Rubin Z, Mautalen C. Osteoporosis with vertebral fractures associated with pregnancy and lactation. Nutrition. 2000;16(11-12):1052-1055.

14. Kaur M, Pearson D, Godber I, Lawson N, Baker P, Hosking D. Longitudinal changes in bone mineral density during normal pregnancy. Bone. 2003;32:449-454.

15. Vujasinovic-Stupar N, Pejnovic N, Markovic L, Zlatanovic M. Pregnancy-associated spinal osteoporosis treated with bisphosphonates: long-term follow-up of maternal and infants outcome. Rheumatol Int. 2012;32:819-823.

16. Varenna M, Sinigaglia L, Binelli L, Beltrametti P, Gallazzi M. Transient osteoporosis of the hip: a densitometric study. Clin Rheumatol. 1996;15:169-173.

17. Ringe JD, Dorst A, Faber H. Effective and rapid treatment of painful localized transient osteoporosis (bone marrow edema) with intravenous ibandronate. Osteoporos Int. 2005;16:2063-2068.

18. Samdani A, Lachmann E, Nagler W. Transient osteoporosis of the hip during pregnancy: a case report. Am J Phys Med Rehabil. 1998;77: $153-156$.

19. La Montagna G, Malesci D, Tirri R, Valentini G. Successful neridronate therapy in transient osteoporosis of the hip. Clin Rheumatol. 2005;24:67-69.

20. Winarno AS, Kyvernitakis I, Hadji P. Successful treatment of 1-34 parathyroid hormone (PTH) after failure of bisphosphonate therapy in a complex case of pregnancy associated osteoporosis and multiple fractures. Z Geburtshilfe Neonatol. 2014;218:171-173.

21. Choe EY, Song JE, Park KH, et al. Effect of teriparatide on pregnancy and lactation-associated osteoporosis with multiple vertebral fractures. J Bone Miner Metab. 2012;30:596-601.

22. Diab DL, Watts NB. Postmenopausal osteoporosis. Curr Opin Endocrinol Diabetes Obes. 2013;20:501-509.

23. Tabb MM, Sun A, Zhou C, et al. Vitamin K2 regulation of bone homeostasis is mediated by the steroid and xenobiotic receptor SXR. J Biol Chem. 2003;278:43919-43927. 
24. Bayram S, Ozturk C, Sivrioglu K, Aydinli U, Kucukoglu S. Kyphoplasty for pregnancy-associated osteoporotic vertebral fractures. Joint Bone Spine. 2006;73:564-566.

25. Tsuchie H, Miyakoshi N, Hongo M, Kasukawa Y, Ishikawa Y, Shimada Y. Amelioration of pregnancy-associated osteoporosis after treatment with vitamin $\mathrm{K}_{2}$ : a report of four patients. Ups J Med Sci. 2012;117: $336-341$
26. Iwamoto J, Takeda T, Ichimura S. Treatment with vitamin D3 and/or vitamin K2 for postmenopausal osteoporosis. Keio J Med. 2003;52: $147-150$.

Therapeutics and Clinical Risk Management

\section{Publish your work in this journal}

Therapeutics and Clinical Risk Management is an international, peerreviewed journal of clinical therapeutics and risk management, focusing on concise rapid reporting of clinical studies in all therapeutic areas outcomes, safety, and programs for the effective, safe, and sustained use of medicines. This journal is indexed on PubMed Central, CAS,
EMBase, Scopus and the Elsevier Bibliographic databases. The manuscript management system is completely online and includes a very quick and fair peer-review system, which is all easy to use. Visit http://www.dovepress.com/testimonials.php to read real quotes from published authors.

Submit your manuscript here: http://www.dovepress.com/therapeutics-and-clinical-risk-management-journal 